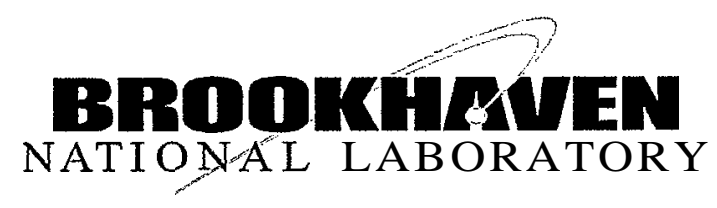

BNL-73482-2005-CP

\title{
Helium Flow Induced Orbit Jitter at RHIC
}

\author{
C. Montag, P. He, L. Jia, A. Nicoletti, T. Satogata, J. Schmalzle, \\ T. Tallerico
}

\author{
Presented at the Particle Accelerator Conference(PAC'05) \\ Knoxville, Tennessee \\ May 16-20,2005
}

\author{
Collider-AcceleratorDepartment \\ Brookhaven National Laboratory \\ P.O. Box 5000 \\ Upton, NY 11973-5000 \\ www. bnl.gov \\ Managed by \\ Brookhaven Science Associates, LLC \\ for the United States Department of Energy under \\ Contract No. DE-AC02-98CH10886
}

This is a preprint of a paper intended for publication in a journal or proceedings. Since changes may be made before publication, this preprint is made available with the understanding that it will not be cited or reproduced without the permission of the author. 


\section{DISCLAIMER}

This report was prepared as an account of work sponsored by an agency of the United States Government. Neither the United States Government nor any agency thereof, nor any of their employees, nor any of their contractors, subcontractors, or their employees, makes any warranty, express or implied, or assumes any legal liability or responsibility for the accuracy, completeness, or any third party's use or the results of such use of any information, apparatus, product, or process disclosed, or represents that its use would not infringe privately owned rights. Reference herein to any specific commercial product, process, or service by trade name, trademark, manufacturer, or otherwise, does not necessarily constitute or imply its endorsement, recommendation, or favoring by the United States Government or any agency thereof or its contractors or subcontractors. The views and opinions of authors expressed herein do not necessarily state or reflect those of the United States Government or any agency thereof.

FOR UNCLASSIFIED, UNLIMITED STIPRODUCTS

Available electronically at:

OSTI:

http://www.osti.gov/bridge

Available for a processing fee to U.S. Department of Energy and its contractors, in paper from:

U.S. Department of Energy

Office of Scientific and Technical Information

P.O. Box 62

Oak Ridge, TN 37831

Phone: (865) 576-8401

Facsimile: (865) 576-5728

E-mail: reports@adonis.osti.gov

National Technical Information Service (NTIS):

Available for sale to the public from:

U.S. Department of Commerce

National Technical Information Service

5285 Port Royal Road

Springfield, VA 22131

Phone: (800) 553-6847

Facsimile: (703) 605-6900

Online ordering: http://www.ntis.gov/ondering.htm

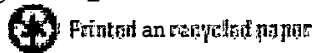




\section{HELIUM FLOW INDUCED ORBIT JITTER AT RHIC *}

\section{Montag, P. He, L. Jia, A. Nicoletti, T. Satogata, J. Schmalzle, T. Tallerico, Brookhaven National Laboratory, Upton, NY 11973,USA}

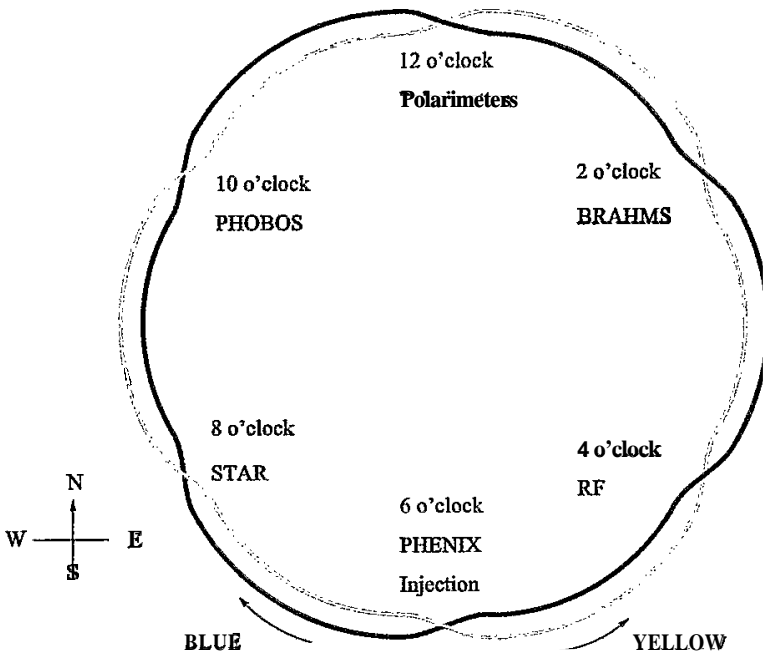

Figure 1: Schematic overview of the RHIC colliderr with its six interaction regions.

\begin{abstract}
Horizontal beam orbitjitter at frequencies around $10 \mathrm{~Hz}$ has been observed in RHIC for several years. The distinct frequencies of thisjitter have been found at superconducting low-beta quadrupoletriplets around the ring, where they coincide with mechanical modes of the cold masses. Recently, we have identified liquid helium flow as the driving force of these oscillations.
\end{abstract}

\section{INTRODUCTION}

THe Relativistic Heavy Ion Collider (RHIC) at Brookhaven National Laboratory consists of two superconducting storage rings which intersect at six interaction points around the $3.8 \mathrm{~km}$ circumference of the machine, as schematically shown in Figure 1. Horizontal orbitjitter at frequencies around $10 \mathrm{~Hz}$ can be detected in both rings during regular machine operations [1]. The amplitude of this oscillation scales with the square root of the horizontal $\beta$-function at any location around the ring, indicating multiple sources. Given a normalized $6 \sigma$ emittance of $E=10 \pi \mathrm{mm}$ mrad of the $250 \mathrm{GeV}$ proton beam, the orbit jitter amplitude correspondsto roughly $5 \ldots 10$ percent of the rms beam size. Mechanical vibrations of the superconductinglow- $\beta$ quadrupoletriplets at the six interaction

\footnotetext{
*Workperformed underthe auspices of the U.S. Department of Energy
}

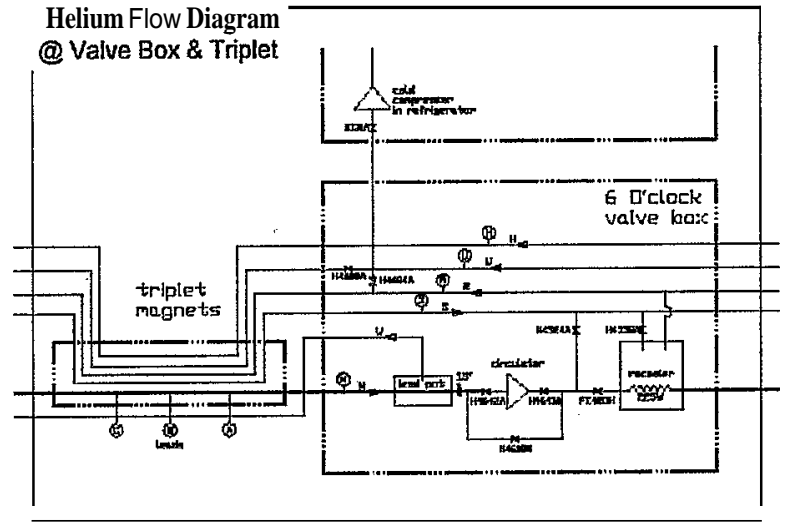

Figure 2: Flow diagram of the RHIC triplet cryostat and the associated valve box at the 6 o'clock location.

regions was identified as the source of the observed beam orbitjitter [1].

A kite-element analysis of the triplet assembly revealed that the observed beam jitter frequencies around $10 \mathrm{~Hz}$ are very close to the lowest mechanical eigenmodes of the triplet [2]. Given the fact that the effect of cooling the cold masses down to liquid helium temperature was not taken into accountin this analysis, the small discrepancybetween calculated and measured frequencies is no surprise, and it is very likely that the observed beam jitter frequencies are indeed eigenfiequencies of the triplet assembly. Therefore, an excitationforce at practically any frequencyaround $10 \mathrm{~Hz}$ would cause mechanical vibrations of the triplets at their eigenfiequencies, and in tumlead to beamjitter at the observed frequencies.

To investigate the excitation force causing the triplets to vibrate at their eigenfiequencies, experiments were performedinvolvingthe cryo system. These experimentsindicate that helium pressure oscillations my be the root cause of the observedbeamjitter.

\section{HELIUM PRESSURE MEASUREMENTS}

To investigate the possible origin of the observed triplet magnet vibrations, helium pressures in the RHIC cryogenic system were monitored. Figure 2 shows a schematic flow diagram of one RHIC triplet cryostat and its associated valve box. Each triplet cryostat contains five helium transfer lines, supply $(S)$, return @), utility $(U)$, thermal shield $(\mathrm{H})$, and magnet $(\mathrm{M})$ lines. At an operating temperature of 


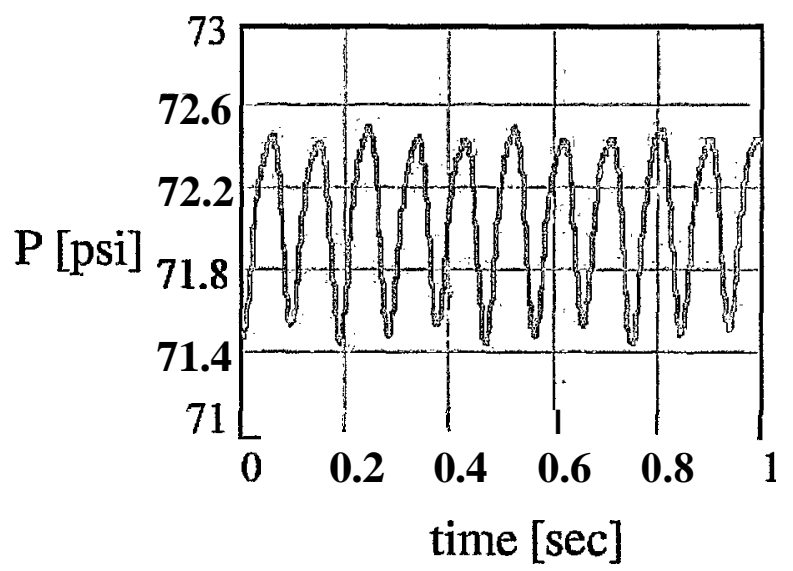

Figure 3: Measured helium pressure $P$ in the magnet line "M" vs. time. The frequency of the obeserved pressure oscillation is $10.7 \mathrm{~Hz}$.

$4.5 \mathrm{~K}$ the helium pressure in the magnet line is about 5 bar. The pressure drop in the magnet cooling loop is about $0.25 \ldots .0 .5 \mathrm{bar}$, and the mass flow rate is $100150 \mathrm{~g} / \mathrm{sec}$. To maintain the closed loop flow, a mechanical circulating compressor is used in each ring, located at the 6 o'clock valve boxes. A mechanicalcold expander is installed in the refrigerator for pressure reduction in the recooler. Three power lead ports for each ring are extended out locally at each triplet cryostat. To monitor helium pressures, pressure transducers were installed in the five helium transfer lines $(S, R, U, H, M)$ at the 6 o'clock valve box and at the six power lead ports of the 6 o'clock triplet. Pressure measurements performed during the FY04 RHIC run showed a $10.7 \mathrm{~Hz}$ oscillation in the " $\mathrm{M}$ "-line and a slow oscillation with a period of about 10 seconds in the "U" line, while the other three lines were very stable [3]. Figure 3 shows the measured pressure during 1 second in the ' $\mathrm{M}$ "--line. This oscillation is caused by the mechanical circulating compressor, and vanishes when this circulator is turned off

\section{OBSERVATIONSWITH BEAM}

To study the effect of the helium circulator on the beam jitter, a dedicated experimentwas performed in April 2004 during which both circulators were turned off while beam jitter in the "BLUE" RHIC ring was observed with the million-turn beam position monitor. This experiment was conducted under "store" conditions when the observed beam orbit vibration amplitudes are largest due to the $\beta$ squeeze at the interaction points which results in large $p$ functions at the vibrating low- $\beta$ quadrupole triplets. $256 \mathrm{k}$ turns were recorded every 30 seconds for about $30 \mathrm{~min}$ utes, during which the circulators were turned off and subsequentlyturned back on aftera few minutes. The horizontal $\mathrm{rms}$ beamjitter amplitude $\sigma_{x}(8.5 \&$ \&.. 14.5 \&) in the frequency range from $8.5 \mathrm{~Hz}$ to $14.5 \mathrm{~Hz}$ was determinedby integrating over the power density spectrum $P(\omega)$ of the

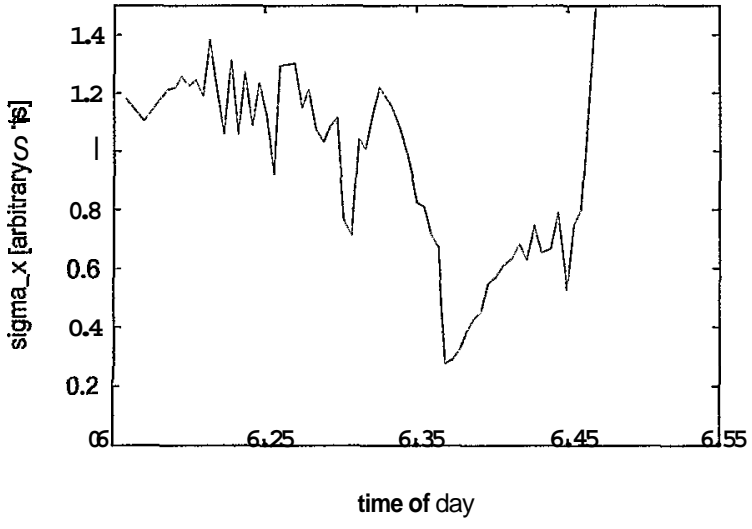

Figure 4: Measured horizontal rms beam jitter in the frequency range from $8.5 \mathrm{~Hz}$ to $14.5 \mathrm{~Hz}$ when the helium circulators in both rings were turned off.

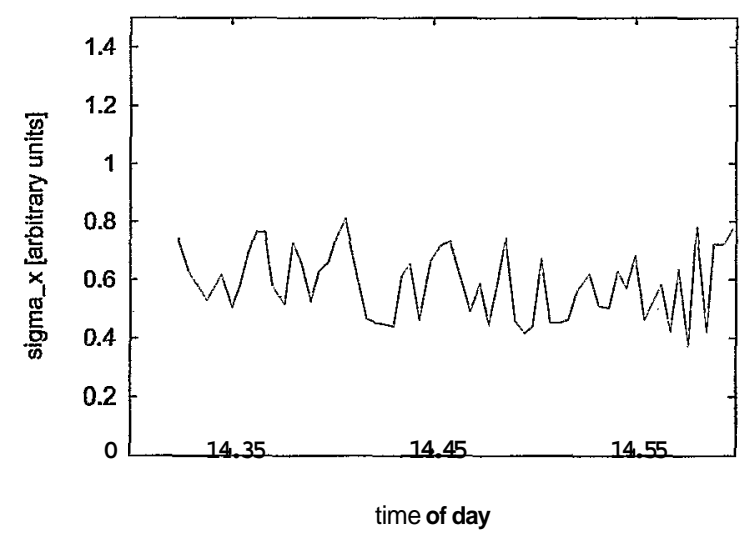

Figure 5: Example of measured horizontal $\mathrm{rms}$ beam jitter in the frequency range from $8.5 \mathrm{~Hz}$ to $14.5 \mathrm{~Hz}$ during regular beam operations in FY05.

turn-by-turn BPM data,

$$
\sigma_{x}(8.5 \mathrm{~Hz} \ldots 14.5 \mathrm{~Hz})=\sqrt{\int_{\overline{2} \pi \cdot 8.5 \mathrm{~Hz}}^{2 \pi \cdot 14.5 \mathrm{~Hz}} P(\omega) \mathrm{d} \omega .}
$$

As depicted in Figure 4, the rms beam jitter amplitude in this frequency band dropped by a factor of five when the helium circulators in both were turned off, and increased again when the circulators were turned on.

To ensure that the observed beam jitter amplitude variation is indeed correlated with circulator operations and not just a natural fluctuation,million-turnBPM data were again taken during regular operations in FY05. Data were processed in the same way as during the dedicatedexperiment described above. Figure 5 shows a typical example of horizontal $\mathrm{rms}$ beamjitter amplitudesduring about 30 minutes.

During regular beam operations, the rms jitter amplitude is rather stable and shows peak-to-peak variations of 
only about 20 percent around the average value, which is far less than the reduction observed when the circulators were turned off during the dedicated experiment(Figure4). The mean rms jitter amplitude during regular operations is about a factortwo smallerthan at the beginning and the end of the dedicated experiment. This may be explainedby the fact that the average helium pressure in the " $\mathrm{M}$ "-line was reduced from 4.7 atm in FY04 to 4.0 atm in FY05.

\section{DISCUSSION}

The cata presented in this paper strongly point at the cryogenic system ass the root cause of the observed beam jitter. However, more experiments are required to confirm this. It is currently planned to increase the helium pressure in the "M"-line from the present 4.0 atm to the FY04 value of 4.7 atm to check whether this influences the beam jitter amplitude. Furthermore, we are planning to repeat the measurement of beam jitter amplitudevs. circulatoron/off to gain more confidence that the effect shown in Figure 4 is more than just a coincidence. Monitoring and frequent logging of cryo parameters such as helium pressure, circulator rpms and helium mass flow rate during this dedicated experimentis expected to contribute to anenhanced understanding of the observed effects.

\section{REFERENCES}

[1] C. Montag, M. Brennan, J. Butler, R Bonati, P. Koello, 'Measurements of Mechanical Triplet Vibrations in RHIC', Proc. EPAC 2002, Paris

[2] J. Schmalzle, unpublished

[3] L. X. Jia, C. Montag, T. Tallerico, W. Hirzel, and A. Nicoletti, 'Pressure oscillations in RHIC cryogenic system", AIP Conf. Proc. 710 154159,2004 